\title{
Photocrosslinkable polymer based on 4-(3-(2,4-dichlorophenyl)-3-oxoprop-1-enyl) phenylacrylate: synthesis, reactivity ratio, and crosslinking studies
}

\author{
J. Suresh, S. KARThiK, A. ARUN* \\ PG \& Research Department of Chemistry, Government Arts College, Thiruvannamalai-606603. Tamilnadu, India.
}

\begin{abstract}
The acrylate monomer was synthesized by two step process. 2,4-dichloro-1-ene(4-hydroxyphenyl)phenone (DHP) was synthesized using 4-hydroxy benzaldehyde and 2,4-dichloro acetophenone. 4-[3-(2,4-dichloro-phenyl)3-oxoprop-1-en-1yl]phenylacrylate (DCP) was prepared by reacting DHP with acryloyl chloride. The synthesized monomer was copolymerized with 2-hydroxyethyl acrylate and styrene using solution polymerization technique. Monomer and polymers were characterized by IR, NMR and UV techniques. The average molecular weight of the polymer was around $4000 \mathrm{~g} / \mathrm{mol}$. First and second decomposition temperature of the polymers was around $320{ }^{\circ} \mathrm{C}$ and $430{ }^{\circ} \mathrm{C}$, respectively. The reactivity ratio of the polymers was calculated by Fineman-Ross, Kelen-Tudos and extended Kelen-Tudos methods. The synthesized monomer has been less reactive than the commercial monomer. The rate of photocrosslinking increased from $39 \%$ to $99 \%$ due to the using of copolymerization technique.
\end{abstract}

Keywords: chalcone; acrylate; reactivity ratio; photocrosslinking; copolymer

(C) Wroclaw University of Technology.

\section{Introduction}

In recent years, polymers containing photoreactive functional groups have received increasing attention in scientific research since the photochemical reactions can induce many changes in physicochemical properties such as solubility, optical transparency, dielectric constant and refractive index $[1,2]$. At the same time, photosensitive polymers have acquired significant importance in various industrial applications, such as optical waveguide materials [3], macro and microlithography [4], liquid crystalline displays [5], holographic head-up displays [6] and so on. High photosensitivity, good solubility, the ability to form films, good thermal stability, resistance towards solvents after crosslinking are very important for practical application such as photoresists. Chalcone $(\alpha, \beta-$ unsaturated carbonyl) group, among many photosensitive groups such as cinnamoyl, thymine and coumarin, is the most widely investigated and used,

*E-mail: aruna2075@yahoo.co.in because it shows high photoreactivity and is able to achieve high level of photo-crosslinking upon irradiation with UV light even without adding a sensitizer [7]. The photo-crosslinking of the chalconecontaining polymers is attributed to the carboncarbon double bonds of the $\alpha$ - $\beta$-unsaturated carbonyl groups which undergo [2+2] cyclo addition reactions under UV irradiation. Most researches focus on polymers with side-chain chalcone units [8, 9]. Generally, the negative type photoresist system was achieved by the cinnamate derivatives of the polymers. The advantage of the pendant cinnamoyl group is that it has very good resistance towards different solvents and good thermal stability. Therefore, this type of polymers can be used as photosensitive compounds.

Nishikubo et al. [10] claimed that the novel p-alkylcalix[n]arene showed photochemical reactions. Several cinnamate based photocrosslinkable polymers were synthesized by Perny et al. [11]. Subramanian et al. [12] reported the synthesis of several photocrosslinkable polymers containing the p-methoxy (or chloro) substituted chalcone 
moiety. They also claimed that these polymers cannot be sensitized but have high photosensitivity. The liquid crystalline alignment of poly(vinyl cinnamate) and poly(7-methacryloyloxycoumarine) in the presence of linearly polarized UV light was reported by Perny et al. [13]. UV-curable waterborne acrylate polyurethane was synthesized and studied by $\mathrm{Xu}$ et al. [14] for the application in metal iron surface production. Combined with photocrosslinkable property, the degradable properties were studied by Shirai [15].

Finding the reactivity ratio of the comonomer in the copolymer is important to derive some idea about the beahvior of the copolymer towards photoirradiation [16]. The comonomer type and the reactivity of the comonomer in the copolymer play a vital role in photosensitivity as well as in the rate of photocrosslinking. Several methods are available for finding the copolymer composition in the literature. The best known graphical methods are Fineman-Ross, Kelen-Tudos and extended Kelen-Tudos which is based on the trustable ${ }^{1}$ HNMR spectroscopy [17]. Other methods used are elemental analysis, IR, etc. which give the reactivity ratio values but the values are not trustworthy. Several literature studies have been devoted to the reactivity ratios and in most cases, the synthesized monomers were less reactive than the commercial monomers. However, the reactivity of the monomers depends on the functional group which is involved in the polymerization process. For instance, in most cases, the acrylate based monomers polymerize at much faster rates than the vinylic type monomers when subjected to copolymersation.

This paper deals with the synthesis and characterization of the chloro-substituted chalcone and its polymers. In order to increase the photocrosslinking and thermal stability of the polymer, the photoactive monomer was copolymerized with the commercially available monomers, hydroxyethyl acrylate and styrene. The estimation of monomer reactivity ratio is vital for tailoring the properties and therefore it is calculated using the available graphical methods like, Fineman-Ross, Kelen-Tudos and extended Kelen-Tudos methods.
The photcrosslinking properties of the homo- and copolymers were determined using UV-Vis spectroscopic methods.

\section{Experimental}

\subsection{Materials and methods}

4-Hydroxybenzaldehyde and acrylic acid were used as received from Aldrich Chemicals. 2,4dichloroacetophenone (DCA) and Triethyl amine (TEA) were received from SD Fine Chemicals. Ethyl methyl ketone (MEK), acrylic acid (AA) and hydroxyethyl acrylate (HEA) were used as received from Merck. Acryloyl chloride was prepared using commonly known procedure [18]. ALPHA BRUKER FT-IR spectrophotometer was used for recording IR spectrum and the spectra were recorded using $\mathrm{KBr}$ pellet method. ${ }^{1} \mathrm{H}$ NMR spectra of the samples were run on a Bruker FT-NMR spectrophotometer operating at $500 \mathrm{MHz}$ using $\mathrm{CDCl}_{3}$ or $\mathrm{DMSO}^{-\mathrm{d}_{6}}$ as a solvent and tetramethyl silane (TMS) as an internal reference. UV absorption measurements were recorded using LABINDIA model UV 320 instrument by dissolving polymer samples in tetrahydrofuran (THF). The preparation of the monomer 4(3-(2,4-dichlorophenyl)-3-oxoprop-1-enyl) phenylacrylate (DCP) was presented in our previous publication [19].

\subsection{Synthesis of 1-(2,4-dichlorophenyl)-3- (4-hydroxyphenyl)prop-2-en-1-one (DHP)}

The procedure given in our article was used for the preparation of DHP [19] $0.025 \mathrm{~mol}$ (4.73 g) of DCA, $0.025 \mathrm{~mol}(3.05 \mathrm{~g})$ of 4-hydroxy benzaldehyde and $4 \mathrm{~g}$ of sodium hydroxide were used for the preparation of DHP. Yield: $6.9 \mathrm{~g}(89 \%)$ and the melting point was $110{ }^{\circ} \mathrm{C}$ to $112{ }^{\circ} \mathrm{C}$. ${ }^{1} \mathrm{H}$ NMR (500 MHz, $\left.\mathrm{CDCl}_{3}, \delta, \mathrm{ppm}\right): 7.4$ to $7.7(\mathrm{~m}, 7 \mathrm{H}$, aromatic $\mathrm{H})$ and $7.0(\mathrm{~d}, 1 \mathrm{H}$, vinylic $\mathrm{CH})$ and 6.9 $(\mathrm{d}, 1 \mathrm{H}$, vinylic $\mathrm{CH})$. FT-IR $\left(\mathrm{cm}^{-1}\right): 3384(-\mathrm{OH})$, 3030 (aromatic $\mathrm{CH}$-stretching), 2985 (aliphatic $\mathrm{CH}-$ stretching), $1655(\mathrm{C}=\mathrm{O})$ and 1588 (aliphatic $\mathrm{CH}=\mathrm{CH})$. 
2.3. Synthesis of 4-(3-(2,4-dichlorophenyl) -3-oxoprop-1-enyl)phenylacrylate (DCP)

The procedure given in our article was used for the preparation of DCP [19] $0.01 \mathrm{~mol}$ (2.92 g) of EHP, $0.012 \mathrm{~mol}(1.67 \mathrm{~mL})$ of TEA and $0.012 \mathrm{~mol}(1.20 \mathrm{~mL})$ of acryloyl chloride was used for the preparation of DCP. Yield $=2.9 \mathrm{~g}$ (79 \%) and the m.p. is $84{ }^{\circ} \mathrm{C}$ to $86{ }^{\circ} \mathrm{C}$. ${ }^{1} \mathrm{H}$ NMR (500 MHz, $\left.\mathrm{CDCl}_{3}, \delta, \mathrm{ppm}\right): 7.4$ to $8.0(\mathrm{~m}, 7 \mathrm{H}, \operatorname{Ar} \mathrm{H}), 6.8(\mathrm{~m}, 2 \mathrm{H}$, vinylic $\mathrm{CH})$ and 5.9 to $6.1(\mathrm{~m}, 3 \mathrm{H}$, polymerisable $\mathrm{CH})$. FT-IR $\left(\mathrm{cm}^{-1}\right)$ : 3036 (aromatic CH-stretching), 2985 (aliphatic $\mathrm{CH}-$-stretching), $1748(-\mathrm{C}=\mathrm{O}$ of ester), $1686(\mathrm{C}=\mathrm{O}), 1591$ (vinylic) and 1583 (aliphatic $\mathrm{CH}=\mathrm{CH}$ ).

\subsection{Synthesis of poly (DCP)}

DCP (1.0 g) and $0.05 \mathrm{~g}$ of BPO (5 wt.\%) were placed in a polymerization tube containing $10 \mathrm{~mL}$ of MEK. The polymerization tube was degassed and heated at $70 \pm 1{ }^{\circ} \mathrm{C}$ in a thermostatic water bath for $24 \mathrm{~h}$. Poly(DCP) was precipitated by adding the reaction mixture to a large excess of methanol with rapid stirring. Yield $=0.9 \mathrm{~g}(90 \%)$. ${ }^{1} \mathrm{H}$ NMR (500 MHz, DMSO-d 6 , $\delta, \mathrm{ppm}$ ): 7.0 to $8.0(\mathrm{~m}, 9 \mathrm{H}$, aromatic and vinylic $\mathrm{H})$ and 0.9 to $1.6\left(\mathrm{~m}, 3 \mathrm{H}\right.$, alkane). FT-IR $\left(\mathrm{cm}^{-1}\right)$ : 3040 (aromatic $\mathrm{CH}$-stretching), 2986 (aliphatic $\mathrm{CH}-$ stretching), $1744(-\mathrm{C}=\mathrm{O}$ of ester $), 1660(\mathrm{C}=\mathrm{O})$ and 1583 (aliphatic $\mathrm{CH}=\mathrm{CH}$ ).

\subsection{General procedure for the prepara- tion of copolymer}

Copolymerization was done using a solution polymerization technique. Appropriate amounts of monomer 1 and monomer 2 were taken in a polymerization tube containing MEK as a solvent and BPO (2 wt.\%) as a free radical initiator. The reaction medium was made inert by passing the nitrogen gas through the inlet of the polymerization tube. The polymerization was carried out at $70 \pm 1{ }^{\circ} \mathrm{C}$ for a definite period of time to maintain the copolymer conversion below $15 \%$. The polymer solution was then precipitated in methanol and the obtained precipitate was then filtered in the sintered crucible, washed with methanol and weighed.
This method was used for the preparation of the following compounds.

\subsubsection{Synthesis of poly (DCP-co-HEA)}

Different molar ratios of DCP, HEA, $8 \mathrm{~mL}$ of MEK and 2 wt.\% of BPO were used for the synthesis of poly(DCP-co-HEA). ${ }^{1} \mathrm{H}$ NMR $(500 \mathrm{MHz}$, DMSO- $\left._{6}, \delta, \mathrm{ppm}\right): 7.0-8.2(\mathrm{~m}, 9 \mathrm{H}$, aromatic and vinylic $\mathrm{H}), 4.6(\mathrm{~b}, 1 \mathrm{H}$, hydroxyl), $3.6(\mathrm{~d}, 2 \mathrm{H}$, $\left.\mathrm{O}-\mathrm{CH}_{2}\right), 3.4\left(\mathrm{~d}, 2 \mathrm{H}, \mathrm{CH}_{2}-\mathrm{OH}\right)$ and 0.9 to 1.5 $\left(\mathrm{m}, 6 \mathrm{H}\right.$, alkane). FT-IR $\left(\mathrm{cm}^{-1}\right): 3336(-\mathrm{OH})$, 3036 (aromatic $\mathrm{CH}$-stretching), 2986 (aliphatic $\mathrm{CH}-$ stretching), $1740 \quad(-\mathrm{C}=\mathrm{O}$ of ester $), 1670$ $(\mathrm{C}=\mathrm{O})$ and 1582 (aliphatic $\mathrm{CH}=\mathrm{CH}$ ).

\subsubsection{Synthesis of poly (DCP-co-S)}

Different molar ratios of DCP and $\mathrm{S}, 8 \mathrm{~mL}$ of MEK and 2 wt.\% of BPO were used for the synthesis of poly(DCP-co-S). ${ }^{1} \mathrm{H}$ NMR $(500 \mathrm{MHz}$, DMSO-d $\left.\mathrm{d}_{6}, \delta, \mathrm{ppm}\right): 7.0$ to $8.0(\mathrm{~m}, 14 \mathrm{H}, \mathrm{Ar} \mathrm{H})$ and 1.0 to $2.0\left(\mathrm{~m}, 6 \mathrm{H}\right.$, alkane). FT-IR $\left(\mathrm{KBr}, \mathrm{cm}^{-1}\right)$ : 3053 (aromatic CH-stretching), 2927 (aliphatic $\mathrm{CH}-$ stretching), $1737 \quad(-\mathrm{C}=\mathrm{O}$ of ester $), 1658$ $(\mathrm{C}=\mathrm{O})$ and 1600 (aliphatic $\mathrm{CH}=\mathrm{CH}$ ).

\subsection{UV crosslinking studies}

The polymer samples were dissolved in tetrahydrofuran (HPLC grade) and the samples were irradiated using a high pressure mercury lamp (UV source) operating at high frequency at room temperature. The distance between the lamp to that of the sample was $15 \mathrm{~cm}^{-1}$. The photocrosslinking properties of the polymer samples were measured by changing the UV absorption intensities of the chalcone type moiety present in the polymer chain. The rate of disappearance of $>\mathrm{C}=\mathrm{C}<$ of the pendant $\alpha, \beta$-unsaturated ketone unit of the polymer was followed by measuring the UV absorption intensity of the solution (around $310 \mathrm{~nm}$ ) after each exposure interval using the following expression:

$$
\text { Rate of conversion }(\%)=\frac{A_{o}--A_{t}}{A_{o}} \times 100
$$

where $A_{o}$ and $A_{t}$ are the absorption intensities caused by $>\mathrm{C}=\mathrm{C}<$ chromophore after irradiation at the times of $\mathrm{t}=0$ and $\mathrm{t}=\mathrm{t}$, respectively. The following copolymer systems, i.e. 
poly(DCP), poly(DCP-co-HEA) and poly(DCPco-S) were studied for the photocrosslinking by UV irradiation ( $0 \mathrm{~s}$ to $1500 \mathrm{~s}$ ).

\section{Results and discussion}

The monomer 4-[3-(2,4-dichloro-phenyl)3oxoprop-1-en-1-yl]phenyl acrylate (DCP) (Fig. 1) was prepared by two step process and the procedure was published in our previous publication [19]. The poly(DCP-co-HEA) and poly(DCP-co-S) (Fig. 2) were prepared in EMK by a free radical polymerization technique and were characterized by FT-IR, ${ }^{1} \mathrm{HNMR}$ and UV-Vis to confirm the structure. The FT-IR spectrum of the DHP, DCP and poly(DCP) is shown in the Fig. 3 and the spectrum confirms the formation of the desired product. Also, the IR spectrum of the polymer presented in the Fig. 4 confirms that the ester group has been intact during the copolymerization process. The NMR spectra of the monomer and the polymer are presented in Fig. 5 and Fig. 6, respectively. The NMR spectrum of the DCP confirms the formation of the acrylate monomer due to the appearance of a peak at 5.9 and $6.1 \mathrm{ppm}$. Similarly, in the polymer sample, the appearance of a peak around $1 \mathrm{ppm}$ to $2 \mathrm{ppm}$ confirms the formation of the polymer. The thermal stability of the polymers is reported in this paper. Molecular weights of the polymers were determined by GPC using Shimadzu instrument (GPC) using THF as an eluent at a flow rate of $0.3 \mathrm{~mL} / \mathrm{min}$. The weight average molecular weights of the polymers were around $4000 \mathrm{~g} / \mathrm{mol}$. The polydispersity values of the polymers are less than 2, quantitatively suggesting that the polymer have been terminated by disproportion method, which is typical for acrylates.

\subsection{Solubility}

The starting material chalcone DHP and the acraylated derivative DCP are soluble in most of the solvents like ethanol, methanol, hexane, dimethyl sulphoxide (DMSO), dimethylformamide (DMF), acetone but insoluble in water, whereas, the polymers are soluble in high polar solvents like DMSO, DMF, tetrahydrofuran but insoluble in

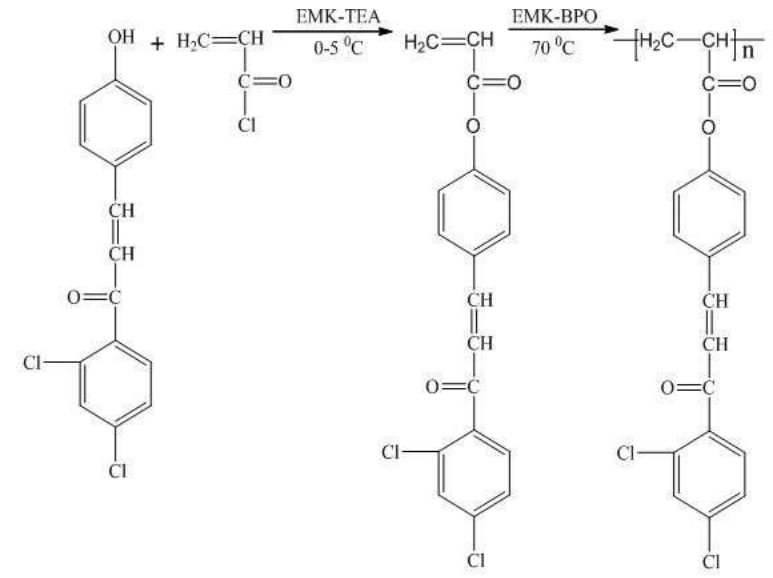

Fig. 1. Synthesis of DCP and poly(DCP).

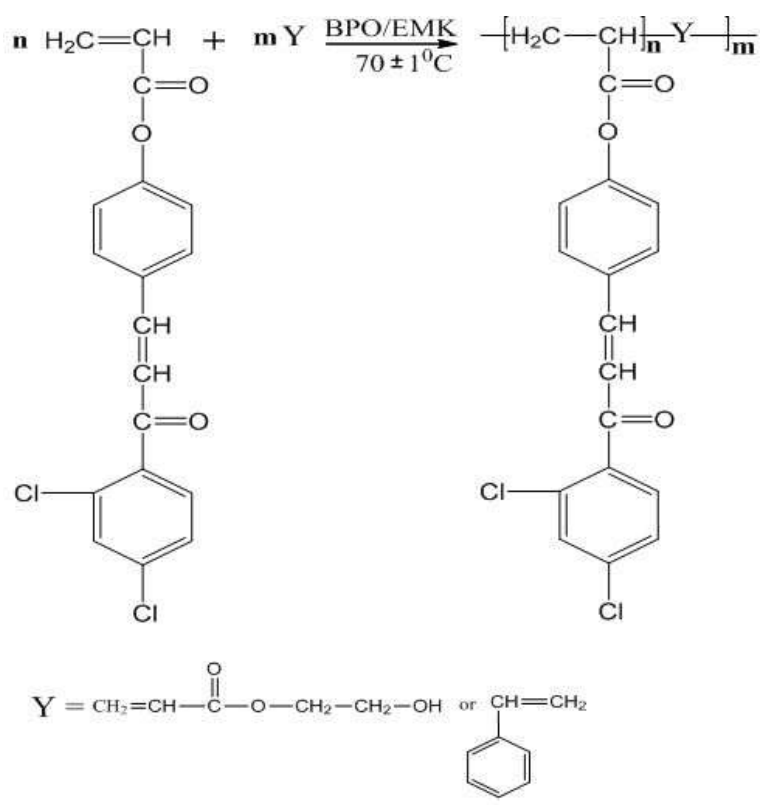

Fig. 2. Synthesis of poly(DCP-co-HEA) and poly(DCP-co-S).

methanol, water, hexane. Also the polymers are not soluble in nonpolar solvents like hexane, benzene and $\mathrm{CCl}_{4}$.

\subsection{Determination of copolymer composi- tion}

The copolymer composition was calculated using ${ }^{1} \mathrm{HNMR}$ spectroscopic technique [17]. The NMR spectrum of the poly(DCP-co-S) and poly(DCP-co-HEA) 


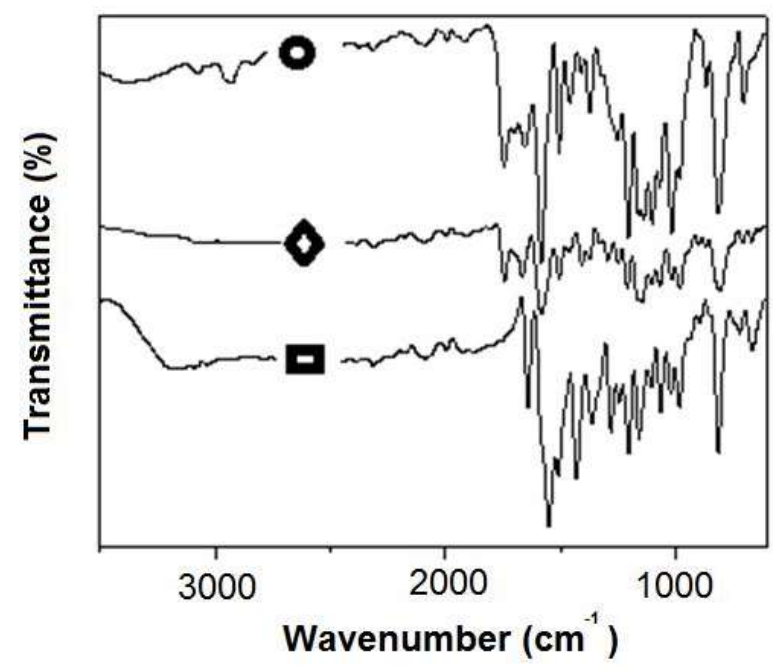

Fig. 3. FT-IR spectra of DHA: $\mathbf{\square}$; DCP: $\downarrow$ and poly(DCP): •.

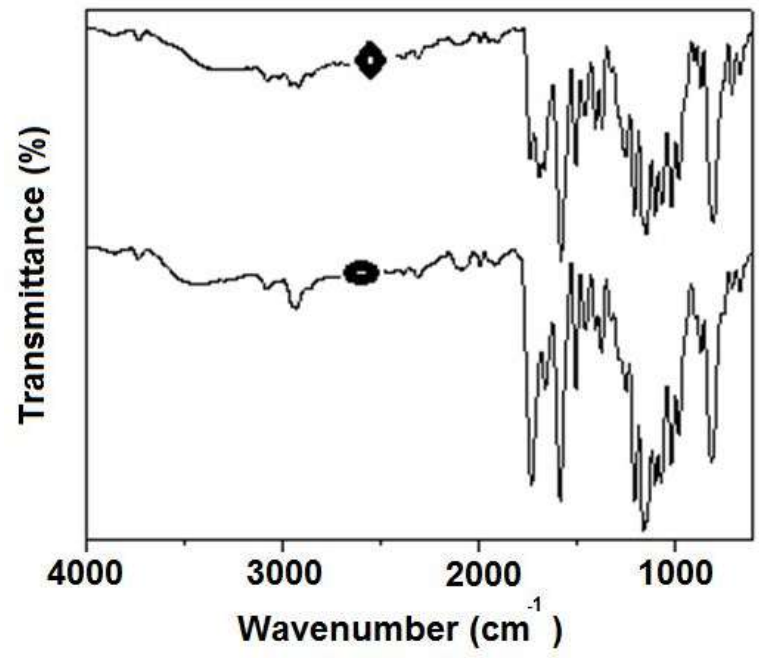

Fig. 4. FT-IR spectra of poly(DCP-co-HEA): • and poly(DCP-co-S):

is presented in the Fig. 6a and Fig. 6b, respectively. From the spectrum, it is evident that the polymer contains both monomers in its chain. The ${ }^{1} \mathrm{HNMR}$ spectrum of the poly(DCP-coHEA) shows a signal at 0.9 to $1.5 \mathrm{ppm}$ for HEA and around 7.5 to $8.2 \mathrm{ppm}$ for DCP system in the copolymer. Since these signals are well separated from each other, the integral values of these two signals can be conveniently taken for calculating the molar fraction of monomers DCP and HEA

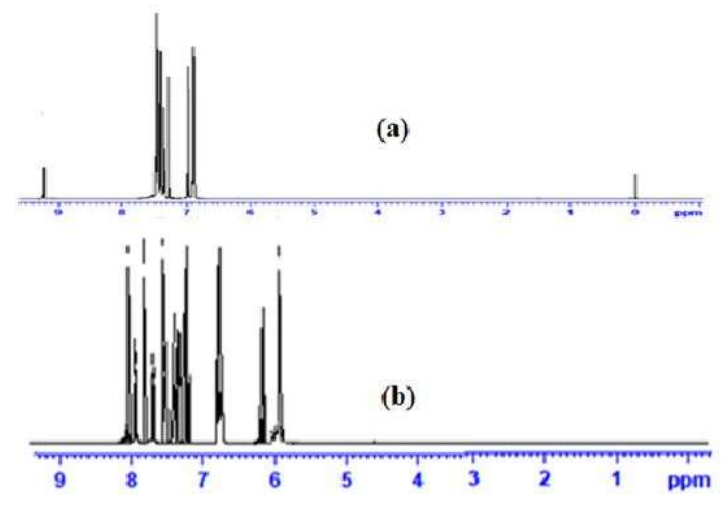

Fig. 5. ${ }^{1} \mathrm{H}$ NMR spectrum of (a) DHP, (b) DCP.

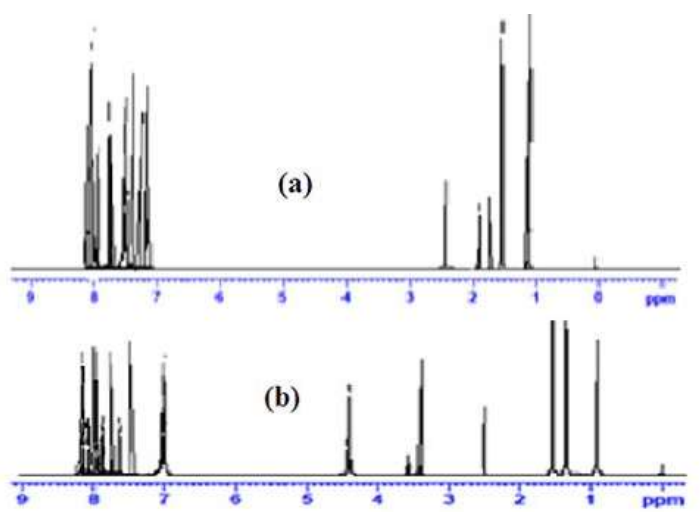

Fig. 6. ${ }^{1} \mathrm{H}$ NMR spectra of (a) poly(DCP-co-S); (b) poly(DCP-co-HEA).

present in the copolymer chain. Assume $m_{1}$ is the molar fraction of HEA and $1-\mathrm{m}_{1}$ is a mole fraction of DCP in the copolymer chain. For calculating the molar fractions, we have taken up 6 methane protons representing both DCP and HEA unit and 7 aromatic protons representing the DCP:

$$
C=\frac{\text { Integral value of methaneprotons }\left(I_{m}\right)}{\text { Integral values ofaromatic type protons }\left(I_{a}\right)}
$$

$$
C=\frac{3 m_{1}+3\left(1-m_{1}\right)}{7\left(1-m_{1}\right)}
$$

and on simplification:

$$
m_{1}=\frac{7 C-3}{7 C}
$$

Integral values of $I_{m}$ and $I_{a}$ are given in Table 1 . 
Table 1. Molar fraction data for poly(DCP-co-HEA).

\begin{tabular}{|c|c|c|c|c|c|}
\hline \multirow{2}{*}{ Feed composition $\mathrm{M}_{1}$} & \multirow{2}{*}{ Conversion [\%] } & \multicolumn{2}{|c|}{ Integral value } & \multirow{2}{*}{$\mathrm{C}=\mathrm{I}_{\mathrm{m}} / \mathrm{I}_{\mathrm{a}}$} & \multirow{2}{*}{ Copolymer composition $\mathrm{m}_{1}$} \\
\hline & & $\mathrm{I}_{\mathrm{m}}$ & $\mathrm{I}_{\mathrm{a}}$ & & \\
\hline 0.15 & 7.6 & 3.34 & 9.63 & 0.3468 & 0.24 \\
\hline 0.30 & 10.3 & 0.88 & 1.13 & 0.6616 & 0.36 \\
\hline 0.50 & 14.2 & 1.73 & 1.64 & 1.0548 & 0.59 \\
\hline 0.70 & 8.7 & 2.31 & 9.77 & 0.2364 & 0.82 \\
\hline 0.85 & 11.8 & 1.64 & 7.29 & 0.2249 & 0.91 \\
\hline
\end{tabular}

[Monomer $1+$ Monomer 2] $=0.5$ moles/litre Temperature: $70 \pm 1{ }^{\circ} \mathrm{C}$ Initiator: BPO [1\% (w/w) of monomers 1 and 2] Solvent: EMK

For poly(DCP-co-S), the integral value of the signal present at 7.5 to $8.0 \mathrm{ppm}$ (12 protons) represents both DCP and styrene $(\mathrm{S})$, and the integral value of the signal present at $7.0 \mathrm{ppm}$ (2 protons), representing DCP monomer, is taken up for calculating the monomer component present in the copolymer chain. Here $\mathrm{m}_{1}$, is taken as a molar fraction of monomer $\mathrm{S}$ and $\left(1-\mathrm{m}_{1}\right)$ is taken for the DCP monomer present in the copolymer chain. The integral values of $I_{a}$ and $I_{e}$ are presented in Table 2:

$$
C=\frac{\text { Integral value of aromatic protons }\left(I_{a}\right)}{\text { Integral values of vinylic type protons }\left(I_{e}\right)}
$$

$$
C=\frac{5 m_{1}+7\left(1-m_{1}\right)}{2\left(1-m_{1}\right)}
$$

and on simplification:

$$
m_{1}=\frac{7-2 C}{2-2 C}
$$

Integral values of $I_{a}$ and $I_{e}$ are given in Table 2 .

\subsection{Reactivity ratio of the monomers}

The mole fraction curve of the feed and the copolymer of the commercial monomers HEA and styrene (S) are presented in Fig. 7 and Fig. 8, respectively. The molar fraction curves show that the reactivity of the commercial monomers is higher than that of the synthesized monomer DCP. The molar fraction curve also suggests that the polymerization has preceded in a random pathway. In

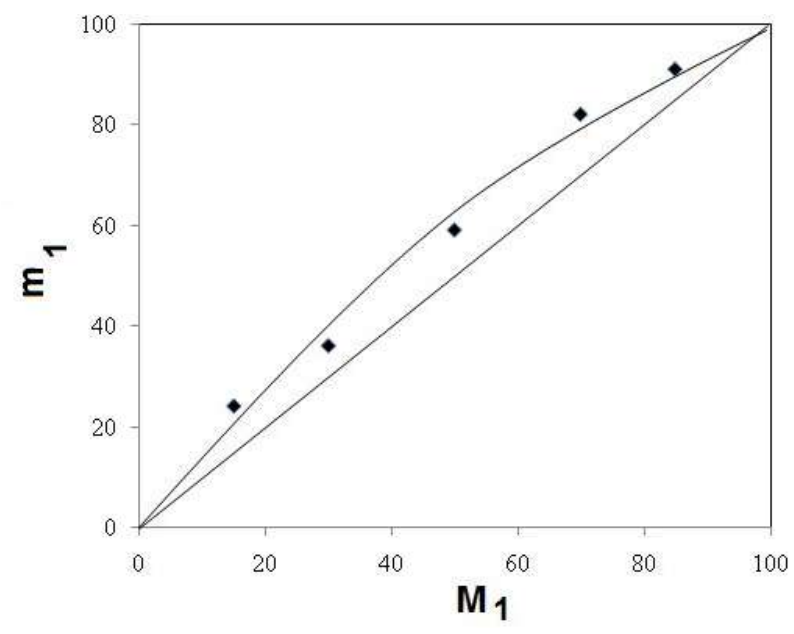

Fig. 7. Molar fraction curve of poly(DCP-co-HEA).

all compositions, the molar fraction of the commercial monomer in the copolymer has always been higher than the feed suggesting that the commercial monomers have a strong preference of entering into the polymer chain. However, compared to the similar system reported in the literature, the reactivity of the DCP is considerably higher [17]. The reactivity ratio of the monomers was calculated using available graphical methods like, (a) Fineman-Ross, (b) Kelen-Tudos and (c) extended Kelen-Tudos. Table 3 shows the reactivity ratio of $r_{1}$ (commercial monomers HEA or S) and $r_{2}$ (monomer DCP). In both the copolymers, the reactivity of the commercial monomer is higher than that in the synthesized monomer DCP. The probable reason may be caused by the bulky nature of the synthesized monomer compared to commercial monomers. This size difference plays 
Table 2. Molar fraction data for poly(DCP-co-S.)

\begin{tabular}{|c|c|c|c|c|c|}
\hline \multirow{2}{*}{ Feed compostion $\mathrm{M}_{1}$} & \multirow{2}{*}{ Conversion [\%] } & \multicolumn{2}{|c|}{ Integral value } & \multirow{2}{*}{$\mathrm{C}=\mathrm{I}_{\mathrm{a}} / \mathrm{I}_{\mathrm{e}}$} & \multirow{2}{*}{ Copolymer composition $\mathrm{m}_{1}$} \\
\hline & & $\mathrm{I}_{\mathrm{a}}$ & $\mathrm{I}_{\mathrm{e}}$ & & \\
\hline 0.15 & 11.5 & 9.98 & 2.25 & 4.44 & 0.27 \\
\hline 0.30 & 15.6 & 5.35 & 0.94 & 5.69 & 0.47 \\
\hline 0.50 & 13.2 & 6.14 & 1.02 & 6.82 & 0.57 \\
\hline 0.70 & 17.2 & 1.31 & 0.12 & 10.91 & 0.75 \\
\hline 0.85 & 9.3 & 4.13 & 0.21 & 19.66 & 0.86 \\
\hline
\end{tabular}

[monomer $1+$ monomer 2$]=0.5 \mathrm{~mol} / \mathrm{L}$ temperature: $70 \pm 1{ }^{\circ} \mathrm{C}$ initiator: $\mathrm{BPO}[1 \%(\mathrm{w} / \mathrm{w})$ of monomers 1 and 2] solvent: EMK

a major role in determining the reactivity ratio of the monomers [20].

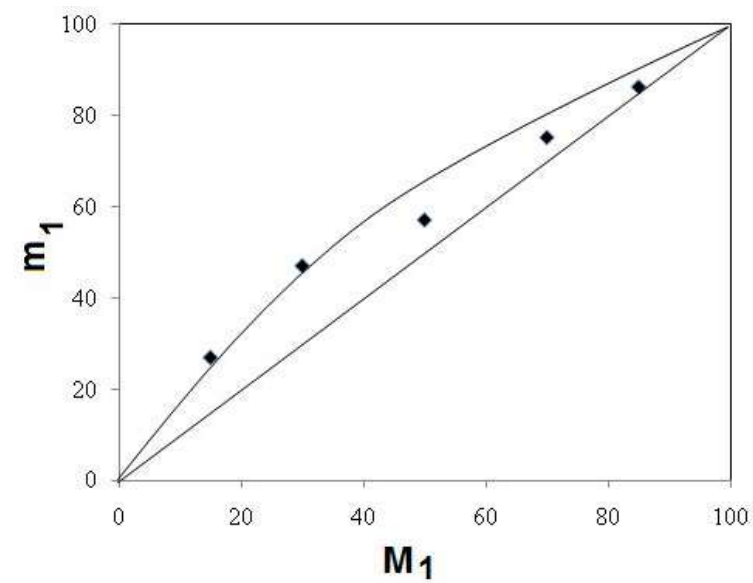

Fig. 8. Molar fraction curve of poly(DCP-co-S).

\subsection{Molecular weights}

The number average and weight average molecular weight of the polymers were determined using GPC method. For poly(DCP), the weight average molecular weight is $\mathrm{M}_{\mathrm{w}}=2.85 \times 10^{3}$, the number average molecular weight is $\mathrm{M}_{\mathrm{n}}=1.88 \times 10^{3}$ and the polydispersity index is $\mathrm{M}_{\mathrm{w}} / \mathrm{M}_{\mathrm{n}}=1.80$. A similar trend has been observed for other polymer samples in this series that are presented in Table 2. The observed polydispersity values confirm that the termination is by disproportion $\left(M_{w} / M_{n}<2\right)$. Acrylates, generally undergo termination by disproportion method.

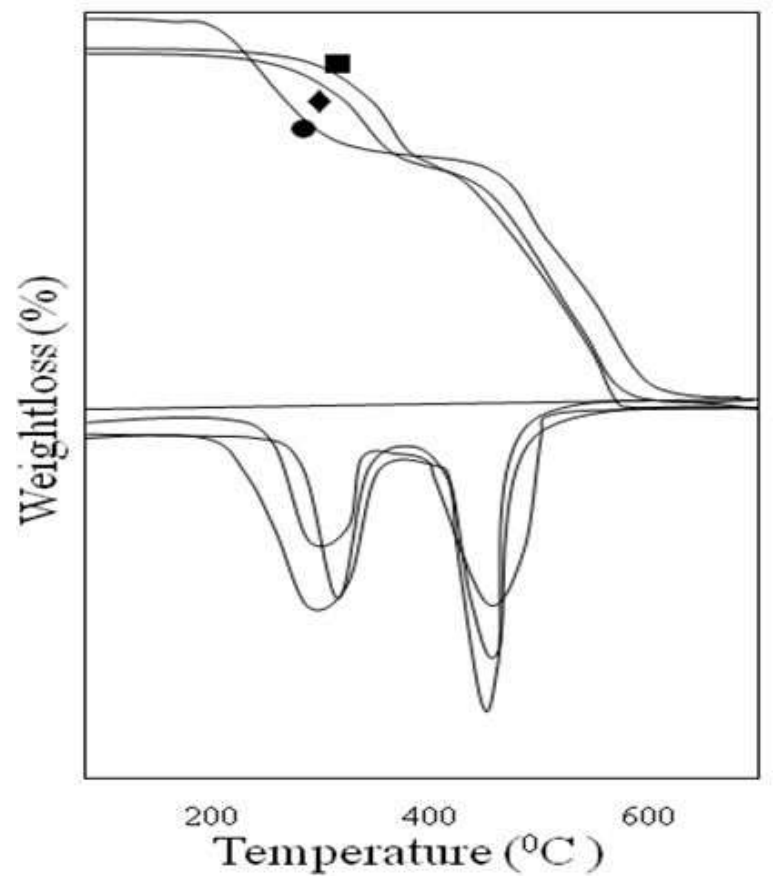

Fig. 9. TGA spectra of poly(DCP): •; poly(DCP-coHEA): $\diamond$ and poly(DCP-co-S):

\subsection{Thermal analysis}

The thermogravimetric curves of the poly(DCP), poly(DCP-co-HEA) (0.41:0.59) and poly(DCP-co-S) $(0.43: 0.57)$ are shown in Fig. 9 and the decomposition temperatures are presented in Table 4. All the polymers undergo two stage decomposition patterns. The first decomposition is centered at $325{ }^{\circ} \mathrm{C}$ and the second decomposition temperature is centered at $430{ }^{\circ} \mathrm{C}$. This type of two-stage decomposition temperature is often observed in similar systems [21, 22]. 
Table 3. $r_{1}$ and $r_{2}$ values of the copolymers.

\begin{tabular}{ccccc}
\hline Polymer & Method & $\mathrm{r}_{1}$ & $\mathrm{r}_{2}$ & $\mathrm{r}_{1} \cdot \mathrm{r}_{2}$ \\
\hline \hline \multirow{3}{*}{ Poly(DCP-co-HEA) } & FR & $1.53 \pm 0.10$ & $0.76 \pm 0.16$ & 1.16 \\
& KT & $1.67 \pm 0.13$ & $0.58 \pm 0.05$ & 0.96 \\
& ex-KT & $1.65 \pm 0.13$ & $0.6 \pm 0.08$ & 0.99 \\
\hline \multirow{3}{*}{ Poly(DCP-co-S) } & FR & $1.1 \pm 0.06$ & $0.66 \pm 0.16$ & 0.73 \\
& KT & $1.25 \pm 0.16$ & $0.45 \pm 0.13$ & 0.56 \\
& ex-KT & $1.31 \pm 0.11$ & $0.49 \pm 0.16$ & 0.64 \\
\hline
\end{tabular}

The higher decomposition temperature of these polymers clearly suggests that these materials have high thermal stability.

\subsection{Photocrosslinking studies of the poly- mer having DCP as a constituent of the polymer chain}

The photocrosslinking properties of the polymers based on DCP having photosensitive chalcone type moiety were studied in detail. The changes in the UV absorption patterns of the polymers containing DCP as a constituent of the polymer chain are presented in the Fig. 10, Fig. 11 and Fig. 12. All the polymers show the absorption maximum around $320 \mathrm{~nm}$ due to the $\pi-\pi^{*}$ transition of $>\mathrm{C}=\mathrm{C}<$ of the pendant chalcone group present in the polymer side chain. When the polymer sample in the solution was irradiated using UV lamp, there was a decrease in the intensity of the absorption maximum around $320 \mathrm{~nm}$. This was due to the formation of the cyclobutane ring by $2 \pi-2 \pi$ cycloaddition of the olefinic double bonds of pendant chalcone units present in the polymer chain [23]. The possible way in which the chalcone polymers were crosslinked when subjected to UV light is shown in Fig. 13.

This type of cyclo-addition of the olefinic bond destroys the conjugation in the $\pi$-electron systems. This is the reason why we observe the decrease in the intensity of the absorption maximum upon irradiation with UV light [24]. Also, the absence of isobestic point in the range of $270 \mathrm{~nm}$ to $280 \mathrm{~nm}$ due to the cis-trans isomerization of the chalcone double bond confirms that the crosslinking is precedent over the cis-trans isomerism (Fig. 13). The photoisomerization of the polymer chain can

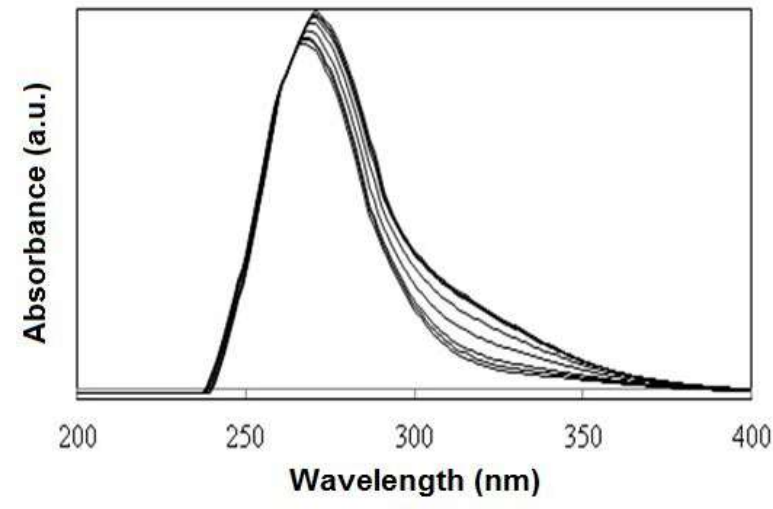

Fig. 10. Shift in the UV absorbance spectrum of poly(DCP) after irradiation period of $0 \mathrm{~s}$ to $1500 \mathrm{~s}$.

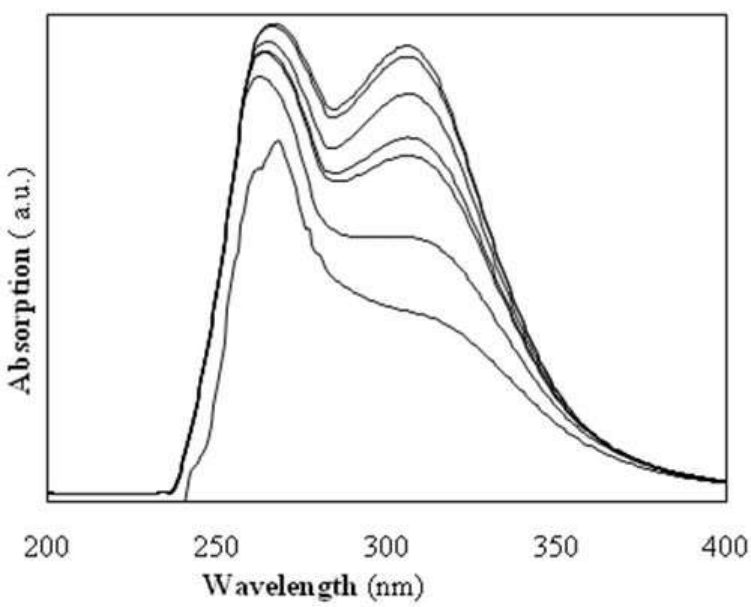

Fig. 11. Shift in the UV absorbance spectrum of poly(DCP-co-S) after irradiation period of $0 \mathrm{~s}$ to $1500 \mathrm{~s}$

be ruled out in this case due to the fact that we have only one crosslinkable double bond which is involved in cyclisation reaction. Several reports showed the isobestic points for the polymer 
Table 4. TGA, molecular weight and UV data of the polymers.

\begin{tabular}{cccccccc}
\hline \multirow{2}{*}{ Polymer } & \multicolumn{2}{c}{ TGA } & \multicolumn{3}{c}{ Molecular weight } & \multicolumn{2}{c}{ UV data } \\
\cline { 2 - 8 } & $1^{\text {st }}\left[{ }^{\circ} \mathrm{C}\right]$ & $2^{\text {nd }}\left[{ }^{\circ} \mathrm{C}\right]$ & $\mathrm{M}_{\mathrm{n}} \times 10^{3}$ & $\mathrm{M}_{\mathrm{w}} \times 10^{3}$ & $\mathrm{M}_{\mathrm{w}} / \mathrm{M}_{\mathrm{n}}$ & Ar. C=C Vinyl C=C \\
\hline \hline Poly(DCP) & 315 & 430 & 1.9 & 2.9 & 1.8 & 265 & 315 \\
Poly(DCP-co-HEA) & 330 & 440 & 2.5 & 3.8 & 1.6 & 260 & 315 \\
Poly(DCP-co-S) & 320 & 430 & 1.9 & 3.1 & 1.7 & 260 & 315 \\
\hline
\end{tabular}

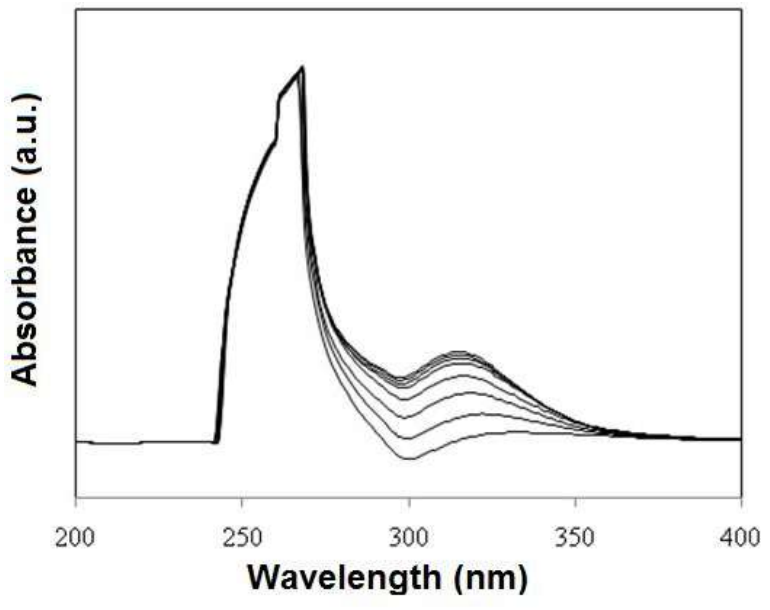

Fig. 12. Shift in the UV absorbance spectrum of poly(DCP-co-HEA) after irradiation period of $0 \mathrm{~s}$ to $1500 \mathrm{~s}$.

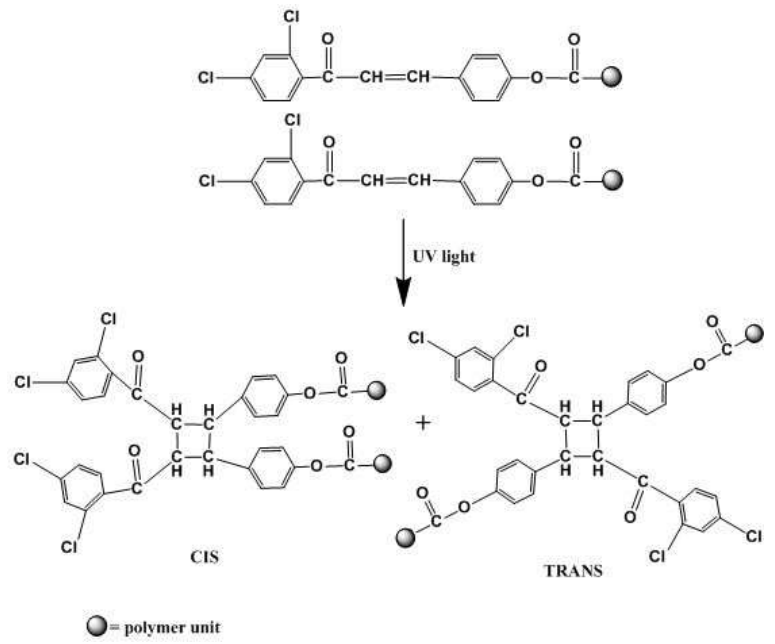

Fig. 13. Effect of UV light on DCP type polymers.

containing two crosslinkable double bond [16]. Also, the photcrosslinking moiety is attached to the polymer backbone and therefore the question of disruption of the chromophore aggregates does not arise here as there is no ordered arrangement in the solution. This further proves that the decrease in the intensity of the UV absorption is due to cyclization and not by cis-trans isomerization [25]. The photosensitivity of the polymer samples was measured as a rate at which the double bond disappears upon irradiation. The photocrosslinking conversion of various polymers having DCP as a constituent of the polymer chain is shown in Table 1. The rate of disappearance of the olefinic bond of the polymer solution after $1500 \mathrm{~s}$ of irradiation follows the order of poly(DCP-coHEA) $>\operatorname{poly}($ DCP-co-S $)>\operatorname{poly}($ DCP $)$.

\subsubsection{Effect of comonomer on the rate of pho- tocrosslinking}

The comparative rate of disappearance of poly(DCP), poly(DCP-co-HEA) (0.41:0.59) and poly(DCP-co-S) (0.43:0.57) is shown in Fig. 14. The figure shows that the rate of disappearance of the double bond of the copolymer is higher than the poly(DCP) clearly suggesting that the special orientation of the polymer chain in the solution plays a major role in deciding the rate of crosslinking. The rate of disappearance of the double bond of poly(HEA-co-DCP) is very high when compared with other polymers like poly(DCP) and poly(Sco-DCP) despite of the fact that the molar fractions of the two commercial monomers in the copolymer chain do not vary much and they are 0.59 and 0.57 for HEA and S, respectively (Table 5). Therefore, the observed enormous increase in the rate of photocrosslinking (almost complete disappearance of the double bond) of double bonds in the copolymer having a HEA as a comonomer can be due to the fact that the presence of an aliphatic chain between the crosslinkable double bond could facilitate the crosslinking process much faster 
Table 5. Rate of disappearance of the olefinic bond.

\begin{tabular}{ccccccc}
\hline \multirow{2}{*}{ I.T } & \multicolumn{2}{c}{ Poly(DCP) } & \multicolumn{3}{c}{ Poly(DCP-co-HEA) } & \multicolumn{2}{c}{ Poly(DCP-co-S) } \\
\cline { 2 - 7 } & A (310 nm) & C [\%] & A (316 nm) & C [\%] & A (312 nm) & C [\%] \\
\hline \hline 0 & 1.709 & 0 & 0.804 & 0 & 2.703 & 0 \\
60 & 1.608 & 5.9 & 0.695 & 13.5 & 2.641 & 2.2 \\
180 & 1.532 & 10.3 & 0.671 & 16.5 & 2.402 & 11.1 \\
300 & 1.468 & 14.1 & 0.644 & 19.9 & 2.130 & 21.2 \\
600 & 1.286 & 24.7 & 0.480 & 40.2 & 2.042 & 24.5 \\
900 & 1.176 & 31.2 & 0.357 & 55.6 & 1.556 & 42.4 \\
1200 & 1.043 & 38.9 & 0.188 & 76.6 & 1.054 & 61.0 \\
1500 & 1.040 & 39.2 & 0.005 & 99.3 & 0.992 & 63.3
\end{tabular}

IT $=$ irradiation time in seconds, $\mathrm{A}=$ absorbance value and $\mathrm{C}=$ crosslinking percentage.

than the aromatic counterpart (styrene). The comonomer HEA present in the polymer chain provides the flexibility to the polymer backbone thereby providing proper orientation for the cyclobutane ring formation [16]. The rate of photocrosslinking was increased in the order of poly(DCP-co-HEA) $>$ poly(DCP-coS) $>\operatorname{poly}(\mathrm{DCP})$.

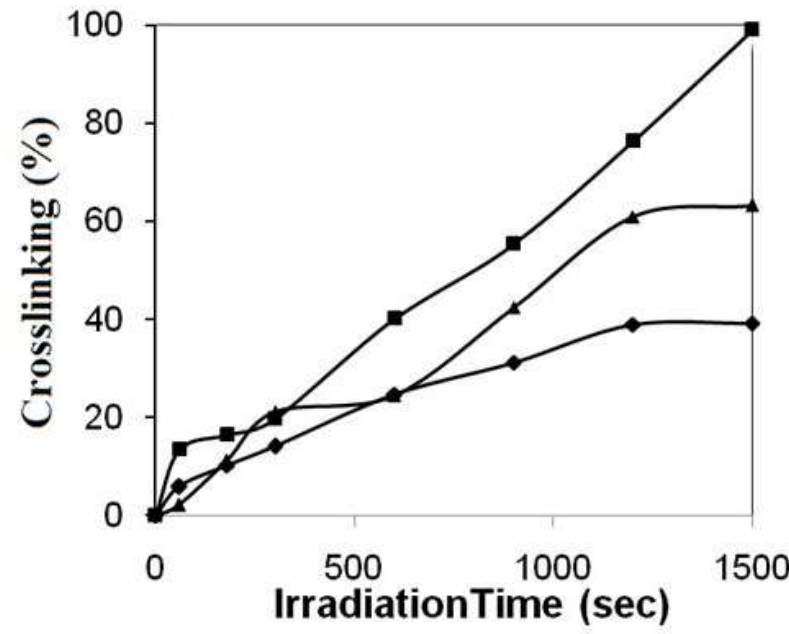

Fig. 14. Rate of disappearance of $>\mathrm{CH}=\mathrm{CH}<$ of $\checkmark$ : poly(DCP); $\mathbf{\Delta}$ : poly(DCP-co-S); poly(DCP-co-HEA).

Though we may not be able to quantify the effect of the comonomers on the rate of photocrosslinking, we are convinced to say that the smaller molecular size comonomer with high reactivity gives assistance to the rate of photocrosslinking. In our investigation, we successfully increased the rate of photocrosslinking from $39.2 \%$ (for poly(DCP)) to $99.3 \%$ (for poly(DCPco-HEA)) (Table 5). This shows that in bulky systems like DCP, the introduction of flexible (or small) molecules into the polymer backbone may increase the rate of photocrosslinking of the polymer sample.

\section{Conclusions}

Novel monomer, 4-(3-(2,4-dichlorophenyl)-3oxoprop-1-enyl)phenylacrylate (DCP) was prepared and copolymerized with HEA and styrene. Poly(DCP), poly(DCP-co-HEA) and poly(DCPco-S) were prepared using the solution polymerization technique. The synthesized polymers were characterized by IR and NMR techniques. The average molecular weight of the synthesized polymers was low, around $4000 \mathrm{~g} / \mathrm{mol}$. Thermal stability of the polymers was very high, first and second decomposition temperature, were around $337{ }^{\circ} \mathrm{C}$ and $461{ }^{\circ} \mathrm{C}$, respectively. The reactivity ratio data reveled that the synthesized monomer was less reactive than the commercial monomer. The UV data showed the characteristic peaks for aromatic and vinylic absorption around $240 \mathrm{~nm}$ and $310 \mathrm{~nm}$, respectively. Photocrosslinking of the polymers was found using the UV-Vis spectrophotometric technique and it was found that in most cases photocrosslinking of the polymer was almost complete 
after 25 minutes of UV irradiation. Overall, in a simple way the rate of photocrosslinking has increased from $39 \%$ to $99 \%$ using copolymerization method.

\section{References}

[1] Rehab A., Salahuddin N., Polymer, 40 (1999), 2197.

[2] Kawatzwni N., Yamanoto T., Ono H., Appl. Phys. Lett., 74 (1999), 935.

[3] Qi Y.H., Ding J.F., Michael D., Jia J., CallenDER C.L., Polymer, 47 (2006), 8263.

[4] Chen H., Yin J., J. Polym. Sci. Pol. Chem., 42 (2004), 1735.

[5] Li X.D., Zhong Z.X., Jin G., LeE S.H., LeE M.H., Macromol. Res., 14 (2006), 257.

[6] Ohe Y., Ito H., Watanabe N., Ichimura K., $J$. Appl. Polym. Sci., 77 (2000), 2189.

[7] Priyarega S., Muthusamy A., Kaniappan K., Murugavel S.C., Des. Monomers Polym., 6 (2003), 187.

[8] Subramanian K., Krishnasamy V., NanjunDAN S., RAmi Reddy A.V., Eur. Polym. J., 36 (2000), 2343.

[9] Balaji R., Nanjundan S., React. Funct. Polym., 49 (2001), 77.

[10] Nishikubo T., Kameyama A., Tsutsui K., $J$. Polym. Sci. Polym. Chem., 39 (2001), 1169.

[11] Perny S., Barny P.L., Delaire J., Dozov I., ForGet S., Auroy P., Liq. Cryst., 27 (2000), 349.

[12] Subramanian K., Krishnasamy V., NanjunDAN S., RAMI REDDY A.V., Eur. Polym. J., 36 (2000), 2343.
[13] Perny S., Barny P.L., Delaire J., Buffetean T., Sourissean C., Dozov I., Forget S., MartienLGARde P., Liq. Cryst., 27 (2000), 329.

[14] Xu J., Rong X., Chi T., Wang M., Wang Y., YAng D., QIU F., J. Appl. Polym. Sci., 130 (2013), 3142.

[15] ShIRAi M., Polym. J., 46 (2014), 859.

[16] Arun A., Reddy B.S.R., J. Polym. Sci. Polym. Chem., 41 (2003), 1632.

[17] Arun A., Reddy B.S.R., J. Polym. Sci. Polym. Chem., 42 (2004), 3433.

[18] Stampel G.M., Cross R.P., Malliella R.P., J. Am. Chem. Soc., 72 (1950), 2899.

[19] Suresh J., Vakees E., KarthiK S., KaYAlvizhi M., ARUN A., Des. Monomers Polym., 17 (2014), 753.

[20] Arun A., Reddy B.S.R., Eur. Polym. J., 40 (2004), 589.

[21] Esquivel-GuZmán J.A., Zaragoza-Galán G., Ortíz-Palacios J., Rivera E., Des. Monomers Polym., 15 (2012), 561.

[22] ViJayanand P.S., Kato S., Koyama M., Satokawa S., Kojima T., Des. Monomers Polym., 10 (2007), 375.

[23] Nishikubo T., Iizawa T., Takahashi E., FumiHIKO N., Macromolecules, 18 (1985), 2131.

[24] Lamaitre E., Coqueret K., Meruier R., ComBIER A.L., Loucheux C., J. Appl. Polym. Sci., 33 (1987), 2189.

[25] Rami Reddy A.V., Subramanian K., Sesha Sainath A.V., J. Appl. Polym. Sci., 70 (1998), 2111.

Received 2016-04-17 Accepted 2016-10-14 